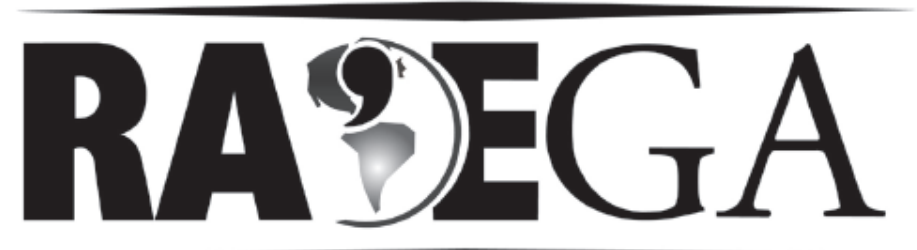

O ESPAÇO GEOGRÁFICO EM ANÁLISE

\title{
ZONEAMENTO DO PARQUE ECOLÓGICO DE OURINHOS SP
}

\section{ZONING OF THE ECOLOGICAL PARK OF OURINHOS SP}

\author{
Luciene Cristina RISSO ${ }^{1}$
}

\section{RESUMO}

O objetivo desse estudo foi realizar um zoneamento do parque ecológico municipal de Ourinhos SP, localizado a sudoeste do Estado de São Paulo, visando subsidiar o planejamento e a gestão desta área. Com esse propósito foi feito um inventário dos recursos paisagísticos do parque com realização de mapeamentos da hipsometria, declividade, uso do solo e zoneamento. A partir deste último, analisamos as possibilidades de implementação de propostas de uso, com os objetivos da conservação da área, visando minimizar os impactos ambientais negativos. Deste modo, esta pesquisa foi de extrema importância, pois permitiu identificar e ordenar no território, áreas ou setores prioritários para o desenvolvimento de atividades, bem como contribuir para a conservação dos patrimônios natural e sociocultural.

Palavras chave: áreas protegidas; mapeamento; gestão ambiental.

\section{ABSTRACT}

The aim of this study was to carry out a zoning in the municipal ecological park of Ourinhos, SP, located southwest of São Paulo State, aiming to subsidize the

\footnotetext{
${ }^{1}$ Geografa. Profa.Dra. da UNESP - campus de Ourinhos SP. email: luciene@ourinhos.unesp.br
} 
planning and management of this area. With this purpose it was made an inventory of the landscape resources of this park with hypsometry, declivity, use of soil and zoning mappings. From this zoning, we analyzed the possibilities of implementing purposes of use, with the objective of preserving this area, minimizing the negative environmental impacts. Thus, this research was of extreme importance, since it allowed to identify and rank, in the territory, areas or sectors that are priority to the development of activities, as well as contribute to the conservation of natural and socio-cultural heritage.

Key words: protected areas; mapping; environmental management.

\section{INTRODUÇÃO}

A idéia da criação de áreas protegidas atualmente está relacionada principalmente com a conservação de ecossistemas e valores culturais. Estas áreas são importantes reservas de recursos naturais, bancos genéticos e em muitos casos, um território cultural exprimindo diferentes valores e relacionamentos com o meio ambiente, ao qual contribuem para a preservação e a conservação das mesmas.

Todavia, a eficácia das áreas protegidas depende de diversos fatores, desde a questão do tamanho, forma da área até a questão do planejamento e gestão ambiental.

Uma maior preocupação com o planejamento e gestão de uma unidade de conservação materializou-se com a aprovação do SNUC - Sistema Nacional de Unidades de Conservação (BRASIL-Lei 9985-2000), importante instrumento técnico jurídico, composto de dois grupos: as unidades de proteção integral e as de uso sustentável, ao qual devem elaborar o seu plano de manejo².

Este plano é "um documento técnico, mediante o qual, com fundamentos nos objetivos gerais de uma unidade de conservação, se estabelece o seu zoneamento e as normas..." (BRASIL, 2000). Nele são recomendados os usos, as formas e a implantação das estruturas físicas necessárias à gestão da unidade. $O$

\footnotetext{
${ }^{2}$ Apesar da exigência no prazo de cinco de anos (encerrado em julho de 2005) para que as unidades de conservação desenvolvessem seu plano de manejo, a maior parte das unidades ainda não possui.
} 
interessante também é a recomendação para que este plano tenha uma construção participativa da população nas etapas do planejamento e gestão.

Para subsidiar esta necessidade, vários pesquisadores têm contribuído com estudos para o planejamento e zoneamento destas áreas, bem como, no sentido de melhorar as metodologias propostas nos roteiros metodológicos para execução destes planos.

No momento em que propomos esta pesquisa havia uma carência de estudos e mapeamentos na área de estudo, que julgamos como fundamentais para o planejamento e a gestão da área, subsidiando um futuro plano de manejo, após a adaptação ${ }^{3}$ de categoria de parque ecológico para outra prevista na Lei 9985/2000. Esta adaptação é essencial para um melhor gerenciamento da área, contemplação de projetos e recursos financeiros.

- Desta forma, os resultados e análises dos mapeamentos ambientais propiciaram o estabelecimento das estratégias de conservação do parque ecológico de Ourinhos (SP), fornecendo subsídios fundamentais para a gestão dos recursos naturais nesta área protegida.

\section{REVISÃo BIBLIOGRAFICA: ÁREAS PROTEGIDAS E A CATEGORIA DE PARQUE ECOLÓGICO.}

Como uma forma de garantir a preservação de amostras do ecossistema, contra o acentuado desenvolvimento urbano-industrial da segunda metade do século XIX, foi criado o primeiro parque nacional do mundo - Yellowstone, em 1872 nos Estados Unidos ${ }^{4}$.

A criação deste primeiro parque recebeu influências das idéias românticas e pelas contribuições da história natural. Seu objetivo estava voltado à preservação da beleza cênica e natural, além de atender à demanda educacional e

\footnotetext{
${ }^{3}$ Não somente a categoria parque ecológico, mas todas as categorias não contempladas neste sistema devem se adaptar.

${ }^{4}$ Embora esta estratégia seja uma das melhores em conservação, o fato de haver necessidade de reservar espaços contra a destruição é triste, pois o ideal seria a conscientização da própria sociedade que gerisse seus recursos de forma integrada, pensando nas demais gerações.
} 
recreacional das populações urbanas. Era, portanto, uma visão preservacionista, já que a idéia era que o parque fosse desabitado, e que as pessoas somente deviam utilizar a área como visitação.

Após "Yellowstone" surgiram novos parques: Canadá em 1885, Nova Zelândia em 1894, Austrália em 1898 e Brasil em 1937. No entanto, os significados do que seria parque, estavam diversificados.

Há críticas ao modelo de parques que foi levado para o mundo. Isto porque nas regiões tropicais estas paisagens não eram desabitadas, pelo contrário, tinham muitas populações tradicionais e indígenas. Infelizmente, algumas destas populações foram expropriadas do seu lugar e quando permaneciam eram proibidas de desenvolverem atividades diretas (como agricultura, caça, coleta, etc.).

Com vistas a unificar os objetivos acerca da categoria parque, dos seus conceitos e práticas, em 1933 realizou-se em Londres a Convenção para a preservação da flora e da fauna para discutir a conceituação de parque (MACHLIS, TICHNELL, 1985 apud MORSELLO, 2001, p.25).

A estratégia de proteção de áreas foi crescendo e o conceito de parque foi sendo transformado, dando origem a novas categorias (como a reserva, por exemplo). Em 1959 a IUCN (União Internacional para a Conservação da Natureza criada em 1948) com o auxílio das Nações Unidas lançou a primeira lista dos parques nacionais e reservas equivalentes. Em 1960 a IUCN estabeleceu a comissão de parques nacionais e áreas protegidas para promover, monitorar e orientar o manejo dos espaços (BENSUSAN, 2006, p.15). Até hoje esta instituição é referência em áreas protegidas.

Várias conferências foram feitas (e são feitas) para a discussão e orientações sobre áreas protegidas no mundo. Em 1962 houve a primeira conferência mundial sobre parques nacionais em Seattle (EUA). Em 1969 foi em Nova Delhi (Índia), onde se procurou "definir um conceito único e permanente para os parques nacionais" (AMEND, AMEND, 1995, apud MORSELLO, 2001, p.25). 
As outras conferências foram em 1972 em Banff, 1982 em Bali, 1992 em Caracas, 2003 em Durban e 2008 em Barcelona.

Como houve uma variedade de categorias de áreas protegidas no mundo, a IUCN desenvolveu em 1978 seu primeiro sistema de categorização (PHILLIP, 2002). Em 1992, durante o IV Congresso Mundial de Parques em Caracas, esta categorização foi reorganizada, e é válida atualmente. Estas são as categorias reconhecidas atualmente pela (IUCN, 1994):

- Categoria la: reserva natural estrita: área natural protegida, que possui algum ecossistema excepcional ou representativo, características geológicas ou fisiológicas e/ou espécies disponíveis para pesquisa científica e/ou monitoramento ambiental.

- $\quad$ Categoria lb: área de vida selvagem: área com suas características naturais pouco ou nada modificadas, sem habitações permanentes ou significativas, que é protegida e manejada para preservar sua condição natural.

- Categoria II: parque nacional: área designada para proteger a integridade ecológica de um ou mais ecossistemas para a presente e as futuras gerações e para fornecer oportunidades recreativas, educacionais, cientificas e espirituais aos visitantes desde que compatíveis com os objetivos do parque.

- Categoria III: monumento natural: área contendo elementos naturais, eventualmente associados com componentes culturais, específicos, de valor excepcional ou único, dada sua raridade, representatividade, qualidades estéticas ou significância cultural.

- $\quad$ Categoria IV: área de manejo de habitat e espécies - área sujeita à ativa intervenção para 0 manejo, com finalidade de assegurar a manutenção de habitats que garantam as necessidades de determinadas espécies. 
- $\quad$ Categoria V: paisagem protegida: áreas onde a interação entre as pessoas e a natureza ao longo do tempo produziu uma paisagem de características distintas com valores estéticos, ecológicos e/ou culturais significativos e, em geral, com alta diversidade biológica.

- $\quad$ Categoria VI: área protegida para manejo dos recursos naturais: área abrangendo predominantemente sistemas naturais não modificados, manejados para assegurar proteção e manutenção da biodiversidade, fornecendo, concomitantemente, um fluxo sustentável de produtos naturais e serviços que atenda às necessidades das comunidades.

- A criação de áreas protegidas é importante estratégia de conservação/preservação dos recursos naturais, diante da ocupação do solo ilimitada e uso predatório dos recursos naturais.

- Os parques protegem os ecossistemas raros ou típicos de determinado bioma e normalmente são áreas de grandes extensões para justamente alcançar a finalidade de conservação.

Segundo dados da World Database on Protected Areas da IUCN existiam em 2003 aproximadamente 100 mil áreas protegidas, tanto terrestres como marinhas, representando $3,4 \%$ da superfície do planeta (BENSUSAN, 2006, p.33).

No Brasil, o modelo da visão preservacionista de Yellowstone foi seguido. O primeiro parque criado foi de Itatiaia em 1937 no Rio de Janeiro. Seguiram-se outros parques e em sua maioria, eram modelos excludentes.

Diegues (1994) chamou esta visão de "mito moderno da natureza intocada". Gómez-Pompa e Kaus (1992, p.273) criticaram o fato de que a noção de um mundo natural "intocado" reflete uma percepção das populações urbanas que vivem distantes da natureza, pois para os grupos indígenas ou tradicionais, por exemplo, a floresta tropical não é selvagem, é sua casa.

Em meados da década de 1970, o Brasil ainda não possuía uma estratégia nacional articulada para estabelecer áreas protegidas. A criação se justificava face as suas belezas cênicas (VIANNA, 1996). 
Em 1979, o IBDF (Instituto Brasileiro de Desenvolvimento Florestal, criado em 1967) elabora o plano de sistemas de unidades de conservação ${ }^{5}$, importante para as bases na criação das unidades, juntamente com o Decreto-Lei n. 084.017 de 1979 (BRASIL, 1979) que aprovou o regulamento dos parques nacionais brasileiros.

De acordo com este plano, que vigorou até a metade de 2000, existiam várias categorias de manejo diferenciadas pelos seus objetivos. Ressalta-se, porém, que muitas das categorias não tiveram amparo legal, o que atrapalhava o andamento da gestão das unidades. Não se seguia o plano, justamente pela falta de amparo legal ${ }^{6}$, e muitas destas categorias não foram implantadas no Brasil, como parques de caça, rio cênico, estradas-parque.

As categorias incluídas neste plano são bem complexas. Sobre isto, a publicação do IPT (Instituto de Pesquisas tecnológicas) de 1992 - "Unidades de Conservação ambiental e áreas correlatas no Estado de São Paulo" mostrou os principais motivos causadores da complexidade: "[...] à falta de uma terminologia comum aos meios técnico e leigo. Os conceitos confundem-se de pessoa para pessoa, de órgão para órgão, evidenciando a necessidade de se resolver esta questão através da normatização" (SILVA, FORNASARI FILHO, 1992, p.5/6).

Os autores desta publicação do IPT ainda mostram que um exemplo de utilização imprecisa de conceitos era a confusão entre os conceitos de preservação e conservação, utilizados como se fossem sinônimos.

As unidades de conservação foram divididas em cinco categorias de manejo pelo plano de 1979 (IBDF, FBCN, 1979):

\footnotetext{
${ }^{5}$ Esta expressão foi criada no Brasil. Nos demais países a expressão utilizada é área protegida.

6 Este plano precisava ter base legal federal, mas somente algumas categorias dispunham de base legal pelas resoluções do CONAMA. Eram elas: área de proteção ambiental, área de relevante interesse ecológico, estação ecológica, floresta estadual (ou municipal), floresta nacional, horto florestal, jardim botânico, jardim zoológico, monumento natural, parque estadual (ou municipal), parque nacional, reserva biológica e reserva ecológica. O restante das unidades do plano foi chamado de áreas correlatas, pois não tiveram diplomas legais (federal, somente decretos de criação estadual sem uma normatização), segundo mostrou a publicação do IPT de Silva e Fornasari (1992).
} 
1- Categoria de importância nacional:

- Parques nacionais

- Reservas biológicas

- Monumentos naturais

- $\quad$ Refúgios da vida silvestre

2- Categoria de manejo complementar:

- $\quad$ Estações ecológicas

- Rios cênicos

- Estradas parque

- Reservas florestais

3- Categoria de manejo adicional:

- Parques naturais

- Florestas nacionais

- Reservas indígenas

- Reservas de fauna

- Parques de caça

- Monumentos culturais

4- Categorias de manejo regional ou local (são aquelas pertencentes a outros níveis de governo):

- $\quad$ Parques estaduais ou municipais

- $\quad$ Reservas biológicas estaduais ou municipais

- $\quad$ Parques de caça estaduais ou municipais

- Outros

5- Categoria de manejo de importância mundial:

- $\quad$ Reservas de patrimônio mundial

- Reservas de Biosfera

De acordo com SILVA e FORNASARI FILHO (1992, p.40) não houve "registro de validade legal deste plano e nem de qualquer outro que trate, de forma conjunta, as unidades de conservação". Os autores dizem ainda que "algumas questões contidas em diplomas que as criam estavam pouco claras, como é o caso, por exemplo, da superposição de umas unidades em algumas localidades".

Deste modo, o Brasil não dispunha de um sistema nacional de unidades de conservação, importante instrumento técnico-jurídico. Esta necessidade fez com que se tramitasse no congresso nacional em 1992 o projeto de lei 2892/92. Mas, somente em 2000 foi aprovada a Lei $9985 / 2000$ do SNUC - Sistema Nacional de Unidades de Conservação do Brasil - SNUC (BRASIL, 2000). 
Este sistema dividiu as unidades de conservação em dois grupos: unidades de proteção integral e unidades de uso sustentável.

As unidades de proteção integral agregam as categorias de: parques nacionais, estação ecológica, reservam biológica, monumento natural e refúgio da vida silvestre. Quando estas categorias são criadas pelo estado ou município, elas são geridas pelos órgãos estaduais ou municipais responsáveis. As categorias do grupo de unidades de uso sustentável são: área de proteção ambiental área de relevante interesse ecológico, floresta nacional, reserva extrativista, reserva de fauna, reserva de desenvolvimento sustentável e reserva particular do patrimônio cultural (BRASIL, 2000).

As categorias de áreas de preservação permanente, reservas legais e terras indígenas, não foram incluídas no SNUC. Vale ressaltar que estas áreas, na maioria dos casos, contribuem em muito para a conservação e preservação dos recursos naturais. No caso das áreas de preservação permanente e reservas legais, Bensusan (2006, p.66) diz que elas "deveriam fazer do SNUC como componentes acessórios que, integrados às áreas protegidas, poderiam transformar o que é, hoje, um conjunto de unidades de conservação em um verdadeiro sistema".

O inédito na criação de categorias foi à categoria de reserva de desenvolvimento sustentável. Ela foi criada para as áreas onde estivessem comunidades tradicionais, permitindo o uso sustentável. Segundo a lei ela é:

Uma área natural que abriga populações tradicionais, cuja existência baseia-se em sistemas sustentáveis de exploração dos recursos naturais, desenvolvidos ao longo das gerações e adaptados às condições ecológicas locais e que desempenham um papel fundamental na proteção da natureza e na manutenção da diversidade biológica.

O objetivo desta categoria é preservar a natureza e, ao mesmo tempo, assegurar as condições e os meios necessários para a reprodução e a melhoria dos modos e da qualidade de vida e exploração dos recursos naturais das populações tradicionais, bem como valorizar, conservar e aperfeiçoar o 
conhecimento e as técnicas de manejo do ambiente, desenvolvido por estas populações (artigo 20 e $\S 1$ da lei 9985/2000 - BRASIL, 2000).

Resumidamente a área deve ser de domínio público, uso regulado, gerido por um conselho deliberativo, permitido a visitação pública, pesquisa científica e exploração sustentável dos recursos naturais. O plano de manejo definirá as zonas de proteção integral, uso sustentável, amortecimento e corredores ecológicos (BRASIL, 2000).

Quanto à categoria de parque, não houve uma mudança dentro da realidade tropical para permitir a presença de comunidades ${ }^{7}$. Pelo contrário, ela continuou dentro de uma visão preservacionista e não acompanhou a evolução do conceito como sugeriu os principais órgãos de conservação internacional como a IUCN.

O que a lei ofereceu foi o reassentamento destas populações pelo Decreto 4340 que regula a Lei. Essas populações serão indenizadas ou compensadas pelas benfeitorias do local e serão realocadas.

Atualmente a recomendação é que a criação de áreas protegidas seja democrática. Nos casos onde houver populações no interior de áreas protegidas, o ideal é que haja consulta das mesmas, desde a etapa da concepção, e que se dê preferência à criação de unidades de uso sustentável (RISSO, 1998; 2001).

Quanto às demais categorias que existiam no plano de 1979, o SNUC não contemplou muitas delas, como é o caso de jardim zoológico, horto florestal, reservas indígenas, parque ecológico, etc.

Referente ao parque ecológico, alvo deste estudo, esta categoria não constava no plano de 1979 com este nome, mas foi criada no Estado de São Paulo como um tipo de parque estadual e não tinha definição clara, até por causa da ausência de um diploma legal federal que normatizasse esta categoria. Silva e Fornasari Filho (1992, p.22) do IPT, explicam melhor esta categoria:

\footnotetext{
${ }^{7} \mathrm{O}$ conceito de comunidades tradicionais foi vetado porque apresentava problemas em sua definição.
} 
Categoria de unidade de conservação existente no Estado de São Paulo que não possui uma definição exclusiva. O Poder Público estadual utiliza esta denominação para instituir áreas cujas características conceituais correspondem àquelas referentes a Parques estaduais. Nos considerandos dos diplomas que criam tais áreas, faz-se referencia à mesma legislação relativa a parques estaduais. Portanto, ainda necessita de conceituação por parte do Poder Público, o termo Parque Ecológico, a fim de balizar a criação de unidades deste tipo. Por ora, valem as mesmas características e conceitos utilizados para os parques estaduais paulistas.

Para suprir esta inópia de conceituação, Leitão Filho e Azevedo (1989, p.11) definiram parque ecológico como uma categoria que "congrega uma série de atividades com objetivos específicos, de uma forma harmônica, com o objetivo final de integrar o homem com o meio ambiente pela valorização da natureza".

Estes autores indicaram também que dentro desta concepção, a idéia de se ter zoológico ${ }^{8}$ deve ser eliminada. A fauna deve ser mantida livre. Em geral, a concepção converge no sentido de serem áreas de conservação, mas com educação e lazer.

Alguns parques ecológicos criados no Estado de São Paulo foram: Tietê em 1976 abrangendo os municípios de São Paulo, Osasco, Carapicuíba e Barueri; Monsenhor Emilio José Salim em 1987 no município de Campinas; Nascentes do Tietê em 1988 no município de Salesópolis e Guarapiranga em 1989 em São Paulo.

Devido à ausência de conceituação e da não inclusão da categoria de parque ecológico no SNUC, há uma dificuldade no processo de gestão e planejamento. Assim, para resolver a questão, é vital uma mudança e readaptação das áreas assim denominadas para outras categorias.

Assim, entendemos importante a adaptação ao SNUC conforme deixa claro o artigo 55 da lei 9985/2000:

\footnotetext{
${ }^{8}$ Há vários parques ecológicos como de São Carlos (SP) que possuem zoológicos e o de Ourinhos (SP) possui animais em cativeiro. Isto mostra a não padronização desta categoria, o que dificulta a gestão.
} 
As unidades de conservação e áreas protegidas criadas com base nas legislações anteriores e que não pertençam às categorias previstas nesta Lei serão reavaliadas, no todo ou em parte, no prazo de até dois anos, com o objetivo de definir sua destinação com base na categoria e função para as quais foram criadas, conforme o disposto no regulamento desta Lei.

Além de dispor das categorias de conservação, a lei estipula sobre a criação, implantação e gestão das unidades. Sobre a criação, são previstos estudos técnicos e consulta pública (exceto reserva biológica e estação ecológica). Essa consulta permite "também mapear os conflitos de interesses da região e superando-os, angariar apoio da população local para a criação da Unidade" (BENSUSAN, 2006, p.63).

Toda unidade deve elaborar o plano de manejo em cinco anos. Segundo a lei, ele é um documento:

(...) técnico mediante o qual, com fundamento nos objetivos gerais de uma unidade de conservação, se estabelece o seu zoneamento e as normas que devem presidir o uso da área e o manejo dos recursos naturais, inclusive a implantação das estruturas físicas necessárias à gestão da unidade (artigo 2, XVII da lei 9985/2000 - BRASIL, 2000).

Para a construção dos planos de manejo estão previstas basicamente as etapas do diagnóstico e a do planejamento. Na fase do diagnóstico o zoneamento é baseado no inventario e mapeamento de atributos naturais (clima, relevo, geologia, hidrografia, solos, etc.), biológicos (vegetação e fauna) e sociais (dados sócio-econômicos, atividades, etc.). Estas informações da área protegida são trabalhadas principalmente por meio de técnicas de geoprocessamento.

A partir destes estudos e associado aos resultados das reuniões técnicas e oficinas de planejamento, as informações são ordenadas espacialmente em formas de zonas, com os usos permitidos, facilitando a gestão deste território. 
O IBAMA apresenta em seu Roteiro metodológico de planejamento (2002) as seguintes zonas a serem consideradas (que são adaptadas a cada realidade):

- Zona intangível: proteção integral dos ecossistemas.

- Zona primitiva: preservação, mas permite pesquisa científica e educação ambiental.

- Zona de uso extensivo: manter um ambiente natural com baixo impacto humano e acesso público (recreação e educação).

- Zona de uso intensivo: permite infra-estrutura, centro de visitantes, museus, etc.

- Zona histórico-cultural: proteção de sítios arqueológicos, paleontológicos e históricos.

- Zona de recuperação: zona provisória. São áreas em recuperação ambiental.

- Zona de uso especial: infra-estrutura administrativa da unidade.

- Zona de uso conflitante: são espaços anteriores à lei e conflitam com os objetivos da unidade.

- Zona de ocupação temporária: áreas onde se concentram as populações residentes que devem ser reassentadas.

- Zona de superposição indígena: áreas de terras indígenas sobrepostas à unidade.

- Zona de interferência experimental: zona específica para estações ecológicas.

Os roteiros metodológicos para a confecção de planos de manejo estão em aperfeiçoamento e são abertos, mas segundo Marques e Nucci (2207) precisam de uma metodologia integradora das informações.

Neste trabalho nossa pretensão foi sugerir uma ferramenta quantitativa para subsidiar o zoneamento desta futura unidade de conservação, e concordamos com os autores acima que no momento do plano de manejo há de se pensar numa metodologia sistêmica e participativa.

\section{CARACTERIZAÇÃO DA AREA DE ESTUDO}

A cidade de Ourinhos - SP está localizada no sudoeste do Estado de São Paulo, cujo processo histórico de ocupação pelo cultivo de café desmatou 
praticamente toda a mata atlântica do interior presente na região. Neste cenário existem hoje poucos remanescentes da floresta estacional semidecidual, sendo o maior deles localizado no parque estadual Morro do Diabo em Teodoro Sampaio. Em Ourinhos SP, o único fragmento desta floresta dentro da área urbana é o Parque Ecológico Tânia Mara Netto Silva, criado em 2002.

O parque está inserido climaticamente numa transição de acordo com Brando e Durigan (2004, apud DURIGAN ET AL, 2004, p.202), caracterizada por verões quentes com "tendência de concentração de chuvas nos meses de verão, precipitação anuais ao redor de $1400 \mathrm{~mm}$ e geadas severas pouco freqüentes, com período de recorrência em torno de 25 anos".

De acordo com o mapa hipsométrico da área da pesquisa (Figura 2) as altitudes presentes na área estão situadas entre 400 e 440 metros. Sendo que, nas áreas do vale do córrego monjolinho as altitudes estão entre 400 e 425 metros e nas áreas ao norte do parque, as altitudes variam de 425 a 440 metros.

Embora as altitudes no setor não sejam muito elevadas, a declividade é acentuada em alguns trechos (Figura 3). Mas, em geral, nota-se que a maior parte do parque possui declividades entre 11 a $20 \%$, pois se trata de vertentes médias em direção a planície aluvial do córrego Monjolinho, importante afluente do rio Paranapanema. Assim, são áreas muito inclinadas onde o escoamento superficial caracteriza-se como rápido e fragilidade ambiental media. $\mathrm{A}$ área é propensa à ação de processos erosivos e a ocupação pode ocorrer desde que acompanhadas de medidas conservacionistas complexas. Aqui nota-se a existência do núcleo de educação ambiental e o inicio das trilhas interpretativas. Além disto, a presença de áreas que estão em recuperação, como é o caso da área do relógio do sol.

No parque adentra o córrego Monjolinho, cuja presença é muito benéfica para a área, pois quanto maior a diversidade de habitats, maior diversidade biológica (PRIMACK; RODRIGUES, 2001). O papel das matas ciliares ${ }^{9}$ para os ecossistemas aquáticos é fundamental, pois ela "[...] exerce função de proteção,

\footnotetext{
${ }^{9}$ As Matas Ciliares estão protegidas pelo código florestal de 15/05/1965 lei no 4.777 alterado pela lei 7.803 de 18/07/1989 que estabelece a preservação permanente as florestas e demais formas de vegetação natural.
} 
filtragem e amortecimento dos impactos provenientes dos ambientes que circundam ao ecossistema aquático" (JORGENSEN, LOFFLER, 1995 apud FERRAZ, 2001, p.108).

Quanto à vegetação o remanescente florestal se classifica como Floresta Estacional Semidecidual Submontana. Para o IBGE (1992, p.21), o conceito ecológico da classe de vegetação característica da floresta Estacional Semidecidual está "condicionado pela dupla estacionalidade climática, uma Tropical com época de intensas chuvas de verão, e outra subtropical sem período seco, mas com seca fisiológica" (...).

As características fisionômicas desta floresta, também conhecida como Floresta Latifoliada Tropical segundo Romariz (1996), têm formas de vida predominantes de Macro e Meso fanerófitas. Entretanto, a superposição de uma em relação à outra estará de acordo com a localização das áreas em clima Tropical ou Subtropical.

A exemplo das espécies encontradas no parque podemos citar a peroba rosa (Aspidosperma polyneuron) que está em perigo de extinção, o Jaracatiá (Jaracantia spinosa), a peroba-rosa e o Pau d'alho. Estas últimas, são indicadoras do padrão de qualidade do solo e normalmente são encontradas nas áreas onde há terra roxa (ROMARIZ, 1996).

As áreas que foram desmatadas no parque antes de sua transformação estão sendo reflorestadas com espécies nativas, outros locais com espécies frutíferas e ainda outros estão em processo de sucessão ecológica. A este respeito, Jordan (1985) apud Tonhasca (2005) diz: "Os distúrbios naturais devem refletir na maior ou menor capacidade do fragmento em se recuperar de acordo com a intensidade, extensão e duração dos mesmos sobre a área verde". Sendo assim, entendemos que o processo de sucessão depende não só do tipo de uso e ocupação anterior ao da utilização atual da área, como também dos graus de intensidade, extensão e duração das atividades desenvolvidas na mesma. E todo o processo de revegetação aumenta o valor ecológico de áreas florestais isoladas. 
Atualmente, o remanescente de estudo, embora situado em área urbana, encontra-se, em relativo equilíbrio ambiental, todavia, vem aumentando a área com espécies nativas, através das ações de reflorestamento e sucessão ecológica.

O desenvolvimento da área com a função de parque público tem, portanto, favorecido o crescimento e a manutenção do remanescente de Mata. Assim, o parque tem se mostrado fundamental para a proteção e conservação dos recursos naturais (hídricos, florísticos e faunísticos) característicos da área de proteção.

Mesmo de tamanho reduzido (10 ha), este fragmento é importante porque proporciona benefícios sobre o clima como já destacou Lombardo (1985). Nas áreas de mata conservada o clima é ameno em relação ao clima subtropical da cidade. Este corresponde a verões quentes e úmidos e invernos frios e secos, sua temperatura tem em média de $21^{\circ}$ Celsius.

Outros benefícios são por "servirem de refúgios para muitas espécies endêmicas" (TURNER \& CORLETT, 1996, apud TONHASCA JUNIOR, 2005, p.109) e alimentam reservatórios de água e mananciais (VIANA \& TABANEZ, 1996, apud TONHASCA JUNIOR, 2005, p.109), além das atividades de recreação e lazer para os usuários.

Sobre a importância dos parques ecológicos, Furegato (2001) diz que estes parques urbanos possuem um caráter distintivo na paisagem urbana e assumem relevante papel na vida cotidiana dos cidadãos, por constituírem espaços que servem como base para as atividades de lazer e recreação ao ar livre e que acomodam múltiplos usos para os residentes locais, especialmente aqueles que não têm acesso a outras áreas verdes fora do perímetro urbano.

Além das atividades de lazer e recreação, possibilitam o desenvolvimento de atividades educativas, culturais e de descanso, importantes funções ligadas às necessidades físicas, psíquicas e sociais dos indivíduos. Em função dos seus elementos bióticos, representam significativo refúgio da vida silvestre. Por outro lado, as áreas verdes urbanas criam um vínculo afetivo entre os moradores. 
Alguns equipamentos de educação ambiental instalados no parque para o alcance destas funções de lazer, ensino e recreação são: relógio do sol, passarelas e observatório suspenso, mini fazenda e viveiros. A principal diversão é a observação e alimentação ${ }^{10}$ dos macacos prego, criados soltos no parque. Entretanto, estes equipamentos são poucos explorados nas atividades de educação ambiental. Não há materiais didáticos e atividades lúdicas com as crianças e grupos que vão até o parque para somente participar de uma trilha monitorada na mata.

\section{PROCEDIMENTOS METODOLÓGICOS}

Para a execução desta pesquisa realizamos revisão bibliográfica sobre o tema, trabalhos de campos na área e mapeamentos como base para o mapa do zoneamento.

Para se atingir o zoneamento, sugerimos uma ferramenta quantitativa, baseada nos atributos físicos, biológicos e sociais da área de estudo. Esta ferramenta além de ser recomendada nos roteiros metodológicos para confecção de planos de manejo é utilizada pelos geógrafos em diversos tipos de zoneamentos ambientais.

Influenciados então pelo método sistêmico, pensamos na elaboração dos mapas temáticos de hipsometria, declividade e uso do solo porque são mapas que permitem conhecer e analisar a área de estudo. Quando integrados, auxiliam a criação de mapas sínteses da paisagem com recomendações de uso, fundamentais para o planejamento ambiental.

Como relatamos na introdução, não havia nenhum mapeamento do parque Ourinhos. O único material disponível encontrado foi uma carta topográfica da década de 1950 na escala de 1:2000 realizado pela prefeitura da cidade.

\footnotetext{
${ }^{10}$ Esta ação dos visitantes alimentarem os macacos é crítica, pois é um risco tanto para os animais como para os visitantes.
} 
Este levantamento topográfico possuía coordenadas locais em sistema métrico, mas não fornecia a origem dessas coordenadas em nenhum sistema (tais como em coordenadas geográficas ou coordenadas UTM). Então, durante o processo de vetorização foi necessário utilizar outra base cartográfica ${ }^{11} \mathrm{com}$ as quadras e a hidrografia para realizar o georreferenciamento das cartas da Prefeitura.

Desde modo o uso das cartas da década de 1950 foi essencial para a geração dos mapas hipsométrico e de declividade.

A hipsometria permitiu visualizar espacialmente a distribuição altimetrica do terreno e os desníveis. As altitudes variaram de 400 a 450 metros na área de estudo. Associado ao mapa de declividade admitiu determinar as velocidades de escoamento superficial e as fragilidades ambientais. Utilizamos as seguintes classes de declividade adaptada de Ross (1994): menores que 5\% (fragilidade ambiental muito baixa e escoamento superficial lento), 6 a $10 \%$ (fragilidade ambiental baixa e escoamento superficial pouco acelerado), 11 a $20 \%$ (fragilidade ambiental media e escoamento superficial rápido), 21 a 30\% (fragilidade ambiental alta e escoamento superficial muito rápido) e 31 a $50 \%$ (fragilidade ambiental muito alta e escoamento superficial muito rápido).

Já o mapa do uso do solo permitiu diagnosticar a vegetação e os usos realizados na área. Foram utilizadas as imagens Quickbird de 2006 para a confecção deste mapa confeccionado no software open source de origem holandesa llwis 3.4. O método empregado foi o visual, que permite mais controle do intérprete sobre os resultados com zoom de 1:1000. Essas imagens estavam originalmente no software Spring e foi necessária a exportação para o llwis. Outros dados no formato do AutoCAD também foram exportados para o llwis, tais como os vetores da trilha, que também precisaram ser georreferenciados. As imagens Quickbird e a base de quadras e hidrografia do Spring já estavam georreferenciadas e foram utilizadas como referência para as demais.

\footnotetext{
${ }^{11}$ Esta base cartográfica de 2004 refere-se a um levantamento da prefeitura de quadras e hidrografia do parque ecológico, mas sem curvas de nível.
} 
Após a execução destes mapas temáticos, o mapa final do zoneamento foi feito segundo os critérios:

1) Presença da floresta estacional semidecidual preservada, sem as trilhas, mais áreas de preservação permanente do córrego monjolinho foram consideradas áreas da zona de preservação.

2) Presença de floresta estacional semidecidual com a presença das trilhas foi considerada a zona de conservação.

3) A área de recuperação diagnosticada no mapa do uso do solo como de ausência e ou/ estagio inicial e médio de sucessão ecológica da floresta estacional semidecidual, mais a área do campo de futebol foram consideradas áreas da zona de recuperação.

4) E por fim, as construções humanas foram incluídas como a zona de uso do parque.

O mapa base (Figura 1) está em 1:5000 para mostrar, além do parque, o entorno e a nascente do córrego Monjolinho. Os mapas finais foram confeccionados em escala de 1:3000 e os mapas de hipsometria (Figura 2) de declividade (Figura 3), uso (Figura 4) e zoneamento (Figura 5) foram impressos em 1:3000. 
BASE CARTOGRÁFICA DO PARQUE ECOLÓGICO DE OURINHOS - SP
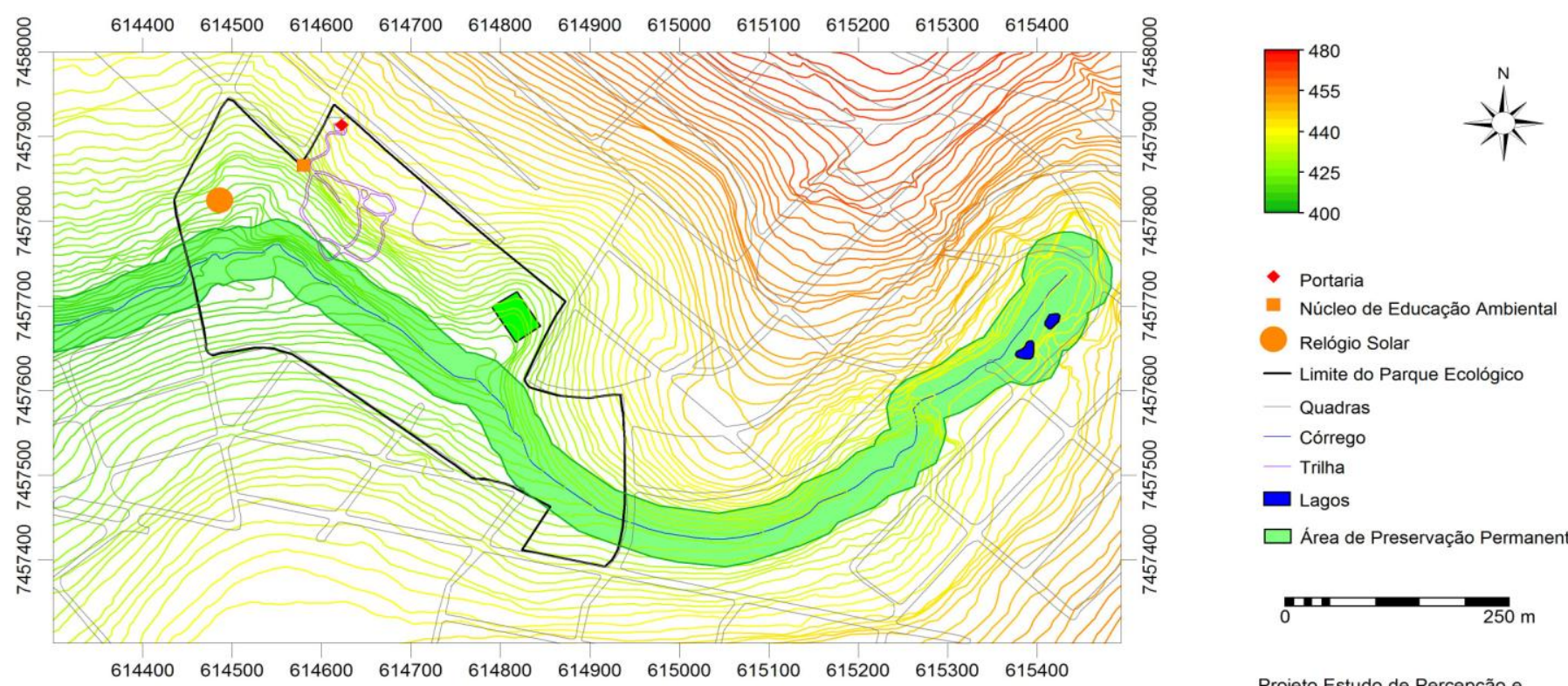

$$
\begin{aligned}
& \text { Portaria } \\
& \text { Núcleo de Educação Ambiental } \\
& \text { Relógio Solar } \\
& \text { — Limite do Parque Ecológico } \\
& \text { - Quadras } \\
& \text { — Córrego } \\
& \text { — Trilha } \\
& \text { Lagos } \\
& \square \text { Área de Preservação Permanente } \\
&
\end{aligned}
$$

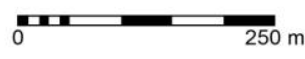

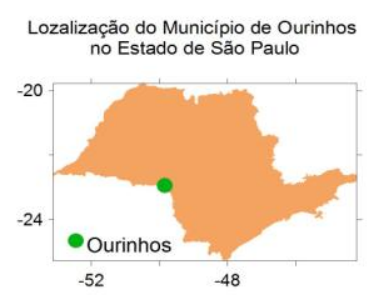
Lozalizacãa do Parque Ecológico
na Área Urbana de Ourinhos

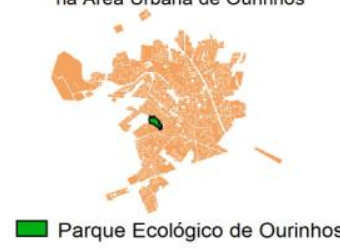

Projeção UTM Fuso 22
Datum SAD 69

$1: 5000$ Projeto Estudo de Percepção e
Conservação Ambiental do Parque
Ecológico de Ourinhos - SP Processo FAPESP 07/01152-8 (2007-2009)

Organização: Risso, L. (2009) Fonte: Fonte:
Prefeitura de Ourinhos (1953)
Cartas topográficas 1.2000

Figura 1: Mapa base do parque ecológico de Ourinhos SP. Fonte: RISSO (2009). 


\section{RESULTADOS}

\section{MAPEAMENTOS E O ZONEAMENTO DO PARQUE ECOLÓGICO DE OURINHOS - SP.}

Como se trata de uma área protegida, o parque ecológico necessita de um zoneamento ambiental, com o objetivo de orientar o planejamento ambiental, pois permite a identificação das características deste local e futuro ordenamento territorial. De acordo com Ross (2006, p.149) as proposições de zoneamento ambiental:

[...] devem refletir a integração das disciplinas técnico - cientificas na medida em que consideram as potencialidades do meio natural, adequando os programas de desenvolvimento e os meios institucionais a uma relação harmônica entre sociedade e natureza, cujo principio básico é o ordenamento territorial calcado nos pressupostos do desenvolvimento com política conservacionista.

O zoneamento do parque foi guiado principalmente pelas informações da vegetação presente no mapa de uso do solo (Figura 4). Os conhecimentos da hipsometria (Figura 2) e declividade (Figura 3) serviram de apoio para as recomendações e propostas de gestão e manejo. Dividimos o parque em quatro zonas (Figura 5):

$\checkmark$ Zona de preservação: áreas com importante interesse biológico/ecológico, que devem ser protegidas, sendo destinadas unicamente ao uso científico e educação ambiental. Nesta área está presente a floresta estacional semidecidual e a área de preservação permanente do córrego Monjolinho.

$\checkmark$ Zona de recuperação: áreas que estão sem vegetação ou com vegetação em recuperação (tanto com espécies nativas ou exóticas). Necessita de ações planejadas para deter a erosão dos solos em decorrência de declividades 
acentuadas e recuperação das matas (tanto atlântica como ciliar).

$\checkmark$ Zona de uso: áreas com construções, como portaria do parque, centro de educação ambiental, relógio do sol e outros equipamentos (áreas de observação), que devem suas ações planejadas para atividades futuras.

$\checkmark$ Zonas de conservação: área com a presença da floresta estacional semidecidual utilizada exclusivamente para a execução das trilhas interpretativas, com respeito à capacidade de suporte da floresta.

A partir deste zoneamento, analisamos as possibilidades de implementação de propostas de uso, com os objetivos da conservação da área e com isto minimizar os impactos ambientais negativos:

Dentro de algumas áreas da zona de uso, poderiam ser construídos brinquedos de madeiras para as crianças propiciando o lazer, ao invés de viveiros com animais presos, (que não é recomendado em parques). Outras atividades seriam a criação de um espaço para convívio social com bancos, centros de exposição artístico-culturais e horta comunitária. É preciso também de mais lixeiras de coleta seletiva no parque. Lembrando que, campo de futebol, viveiros ${ }^{12}$ (com animais presos e exóticos), playgrounds e quadras poliesportivas, não são atividades coerentes com uma área protegida, como dizem Leitão Filho e Azevedo (1989, p. 28): "na concepção do Parque Ecológico deste trabalho, não existe a previsão de construção de quadras poliesportivas ou campos de futebol ou piscinas. Este tipo de lazer não é apropriado a um Parque Ecológico", e nem a idéia de zoológico

\footnotetext{
${ }^{12}$ Trata-se de três viveiros; um com porcos da índia, coelhos, patos, galinhas, tartarugas e outros animais. Este mede aproximadamente $30 \mathrm{~m}$ e $20 \mathrm{~cm}$ de comprimento e $16 \mathrm{~m}$ e $31 \mathrm{~cm}$ de largura. $O$ viveiro menor, com pavão e pato mede por volta de $5 \mathrm{~m}$ e $65 \mathrm{~cm}$ de comprimento com apenas $1 \mathrm{~m}$ e $50 \mathrm{~cm}$ de largura. $O$ último viveiro consta de tartarugas apenas, seu compartimento tem forma arredondada e mede aproximadamente $22 \mathrm{~m}$ e $9 \mathrm{~cm}$ (dados retirados de MATOS E RISSO, 2008).
} 
Na zona de conservação, as trilhas ecológicas merecem destaque, já que os visitantes precisam de uma melhor orientação sobre este remanescente florestal. Quanto à eficácia da conservação biológica, como se trata de um fragmento florestal urbano, o parque tem efeitos de borda. Portanto, para que esta mata continue existindo é necessário um manejo com profissionais qualificados. Esta zona como apresentou as declividades acentuadas ${ }^{13}$ nas trilhas do parque ecológico, isto denota uma adoção de práticas conservacionistas complexas e restrição de uso e principalmente a relevância da preservação da floresta estacional semidecidual.

$\mathrm{Na}$ zona de recuperação, diversas áreas do parque, inclusive as áreas de preservação permanente estão sendo recuperadas com espécies nativas e na área do relógio do sol com espécies frutíferas, entre outras. Estes espaços devem ser recuperados com técnicas apropriadas e planejamento adequado.

Na zona de preservação é necessário um levantamento florístico do local e estabelecer um projeto de corredores ecológicos, unindo as matas ciliares do córrego Monjolinho até o rio Paranapanema. Para o município, a inserção de corredores ecológicos refletiria na manutenção dos recursos hídricos e maior mobilidade da fauna característica da região, o que por sua vez manterá a flora, o solo e o clima em equilíbrio e os remanescentes em fragmentos terão maior chance de conservarem seus recursos.

Nos trechos da margem direita do córrego com declividades muito acentuadas (de 21 a 50\%), as áreas fortemente inclinadas possuem escoamento superficial muito rápido e assim recomenda-se a manutenção da mata ciliar e a recuperação florestal nesta área.

\footnotetext{
${ }^{13}$ Declividades acima de $30 \%$ são consideradas de riscos ambientais (MACHADO, 2000) e não é permitida ocupação de suas encostas (Lei 6766/79)
} 
RA'E GA 23 (2011), p. 489-519

Curitiba, Departamento de Geografia - UFPR www.geografia.ufpr.br/raega/

ISSN: 2177-2738

CARTA HIPSOMÉTRICA DO PARQUE ECOLÓGICO BIÓLOGA DE OURINHOS - SP
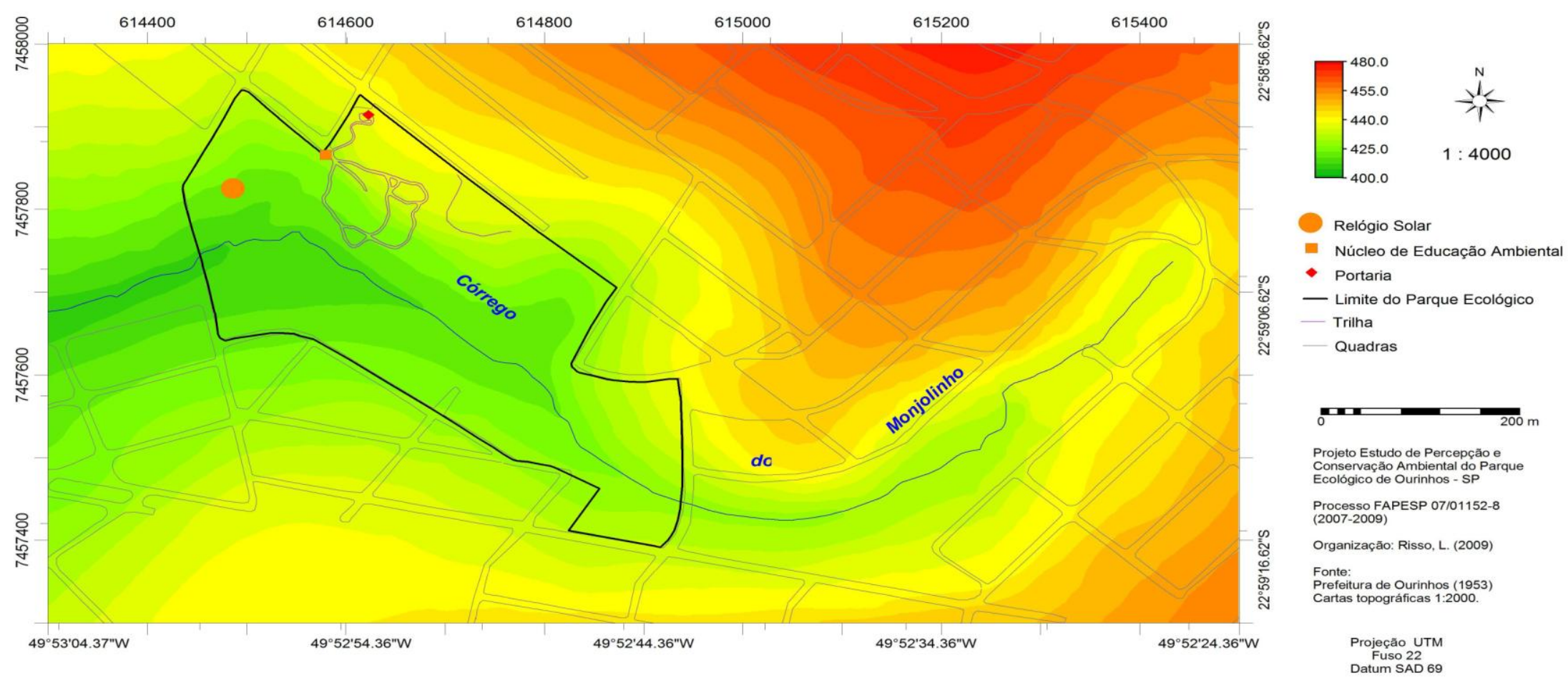

Figura 2: Hipsometria do parque ecológico de Ourinhos SP. Fonte: RISSO (2009). 
CARTA DE DECLIVIDADE DO PARQUE ECOLÓGICO DE OURINHOS - SP
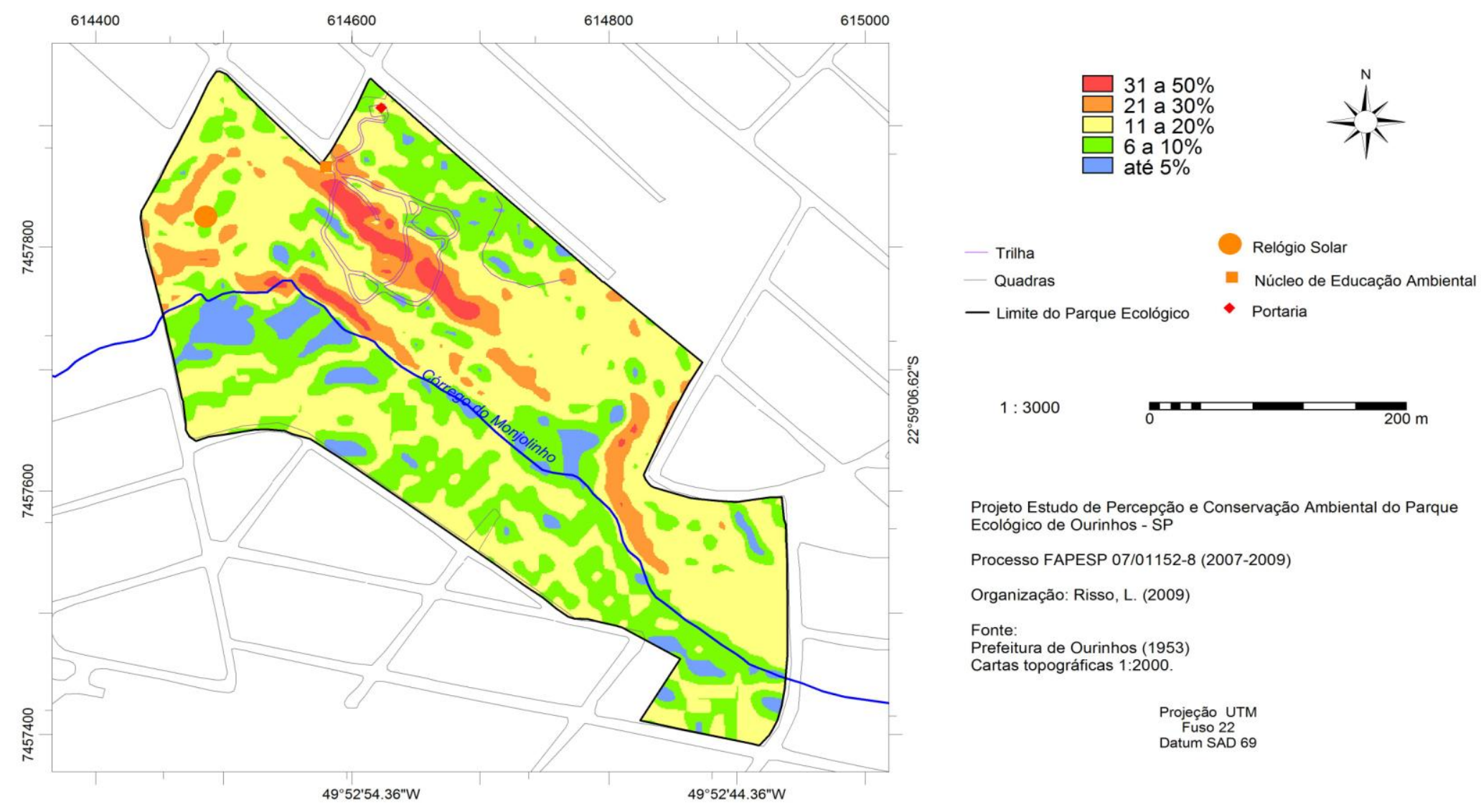

Figura 3: Declividade do parque ecológico de Ourinhos SP. Fonte: RISSO (2009). 
CARTA DE USO E COBERTURA DA TERRA DO PARQUE ECOLÓGICO DE OURINHOS - SP

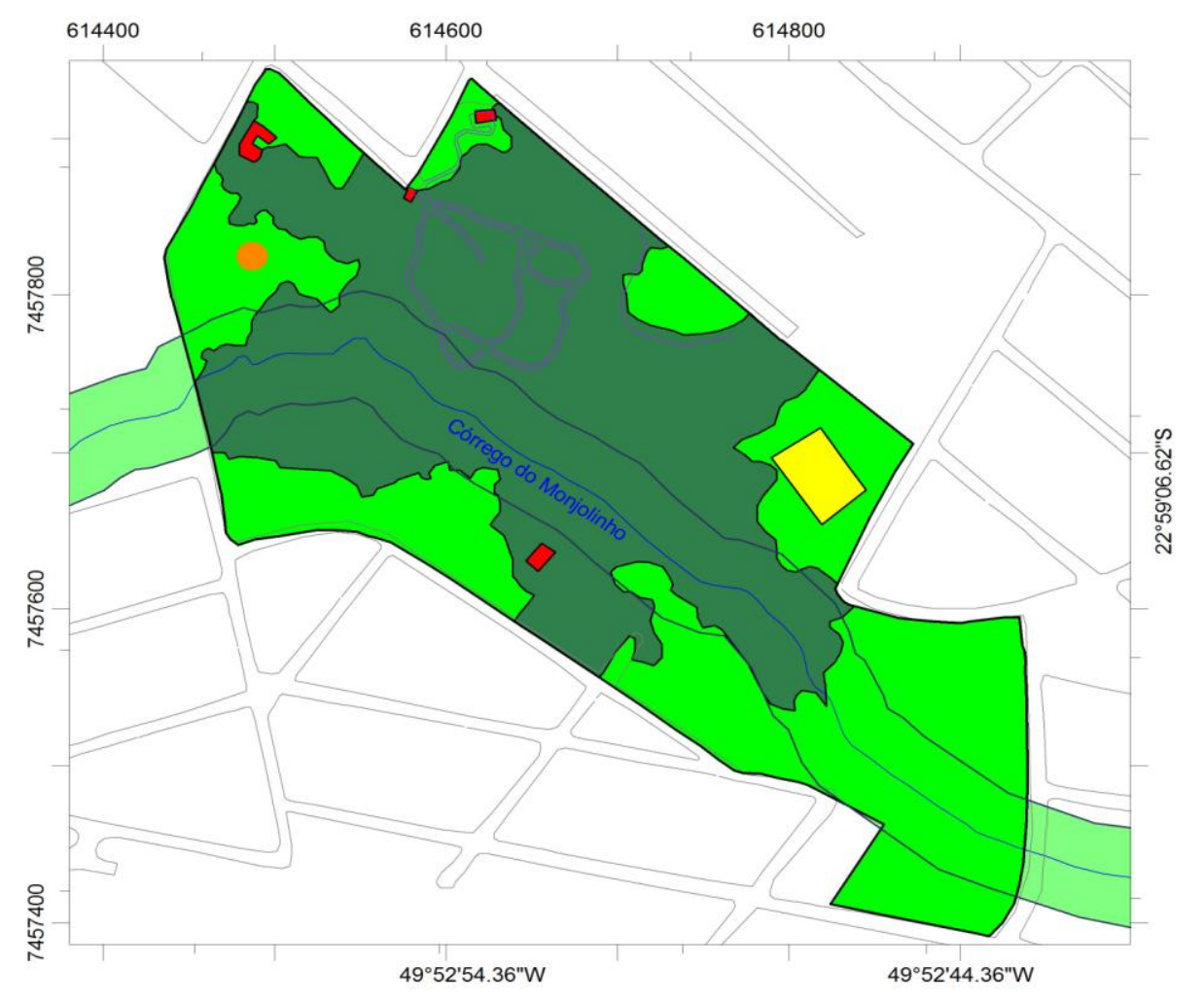

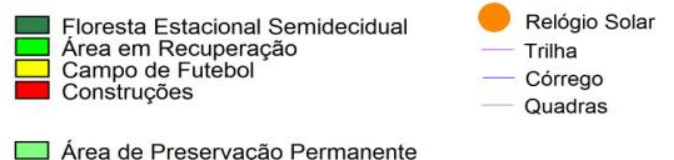

$\square$ Área de Preservação Permanente

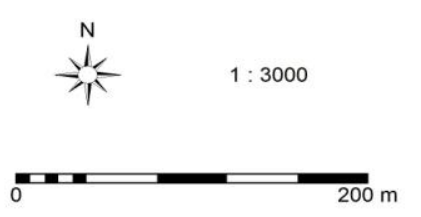
Projeto Estudo de Percepção e Conservação
Ambiental do Parque Ecológico de Ourinhos - SP Processo FAPESP 07/01152-8 (2007-2009) Organização: Risso, L. (2009) Fonte: Imagens Quickbird de 2006 Prefeitura de Ourinhos (1953) Cartas topográficas 1:2000.

\section{Projeção UTM} Fuso 22
Datum SAD 69

Figura 4: Uso e cobertura da terra do parque ecológico de Ourinhos SP. RISSO (2009). 
RA'E GA 23 (2011), p. 489-519

Curitiba, Departamento de Geografia - UFPR www.geografia.ufpr.br/raega/

ISSN: 2177-2738

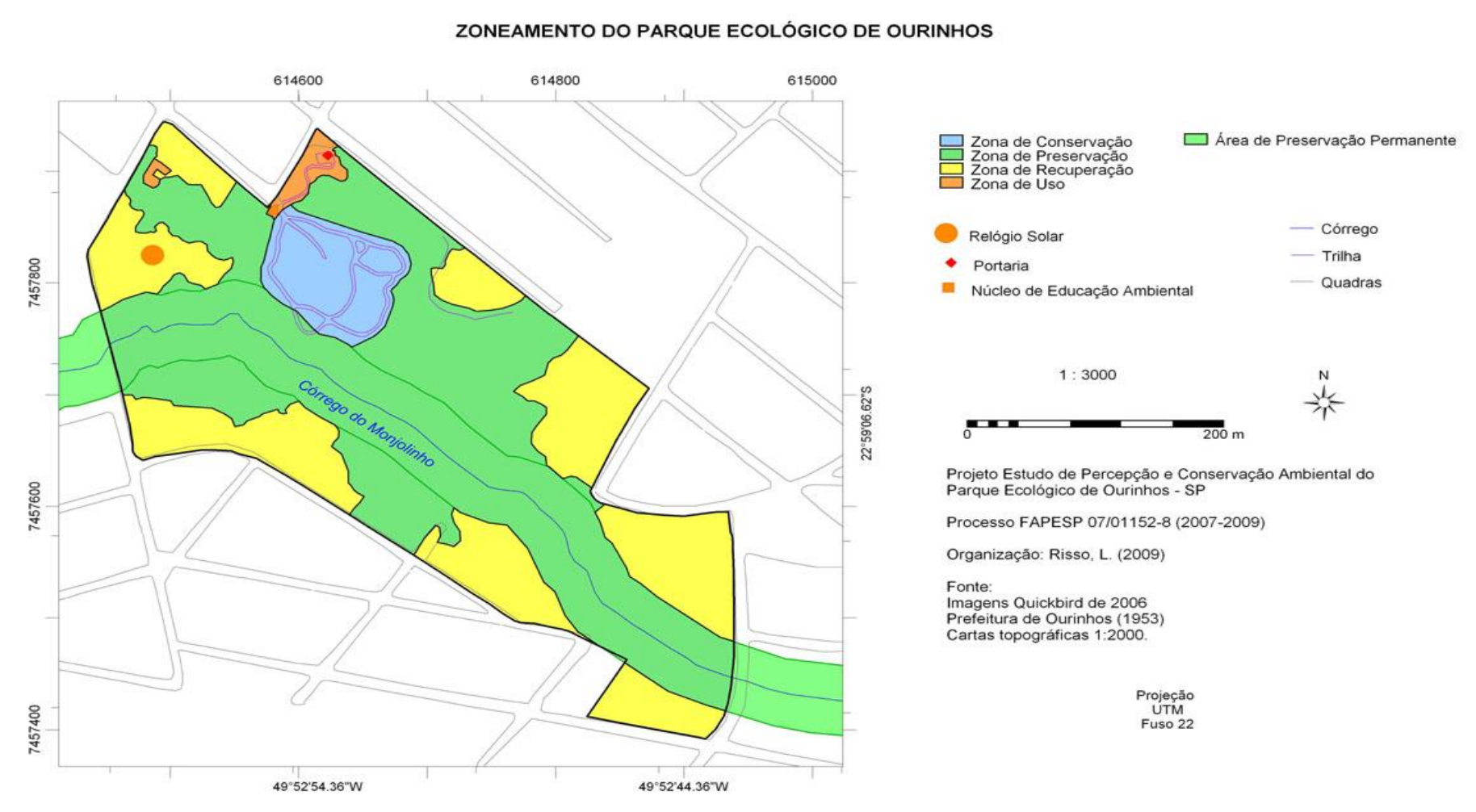

Figura 5: Zoneamento do parque ecológico de Ourinhos SP. Fonte: RISSO (2009). 


\section{CONSIDERAÇÕES FINAIS}

A criação de áreas protegidas foi uma tentativa de manter os ambientes intocados, livres da ação humana, mas o ideal seria realmente novos relacionamentos, novas percepções e atitudes perante a Natureza, na alquimia de diminuir a dicotomia entre esta e a sociedade.

Fundamental também é adequar a categoria de parque ecológico para parque natural municipal segundo o SNUC, pois isto facilitaria a gestão e o manejo da área, já que o ecossistema é remanescente de mata atlântica e permite o desenvolvimento das atividades recreativas, educativas e científicas. Mesmo que nesta categoria haja uma referência para uma área de grandes extensões, a lei brasileira não colocou isto como regra.

Importante dizer que o zoneamento foi essencial, pois permitiu identificar e hierarquizar, no território, áreas ou setores prioritários para o desenvolvimento de atividades, bem como contribuir para a conservação dos patrimônios natural e sociocultural e o estabelecimento de diretrizes para a gestão do mesmo.

Vale ressaltar, que este produto final está aberto, pois para ser um zoneamento final de um plano de manejo, seria preciso integrar mais informações físicas, sociais e planejamento participativo.

\section{REFERÊNCIAS}

BENSUSAN, N. Conservação da biodiversidade em áreas protegidas. Rio de Janeiro: Editora FGV, 2006.

BRASIL. Lei no9985/2000. Cria o Sistema Nacional de Unidades de Conservação - SNUC. Disponível em: http://www.mma.gov.br. Acesso em 20 de julho de 2000.

BRASIL. MINISTÉRIO DA AGRICULTURA. INSTITUTO DE DESENVOLVIMENTO FLORESTAL. FUNDAÇÃO BRASILEIRA PARA A CONSERVAÇÃO DA NATUREZA. Plano do Sistema de Unidades de Conservação do Brasil - II Etapa. Brasília, 1982. 
DIEGUES, A.C. O mito moderno da natureza intocada. São Paulo: NUPAUB/USP, 1994.

DIDHAM, R.K; LAWTON, J.H. Edge structure determines the magnitude of changes in microclimate and vegetation structure in tropical forest fragments. Biotropica 31: 17-30, 1999.

DURIGAN, G.; SIQUEIRA, M.F.; FRANCO, G.A.D. C.; CONTIERI, W.A. A flora arbustivo-árborea do Médio Paranapanema: base para a restauração dos ecossistemas naturais. In: BOAS, O.V.; DURIGAN, G (orgs). Pesquisas em conservação e recuperação ambiental no oeste paulista. Resultados da cooperação Brasil/Japão. São Paulo: Páginas e letras editora e gráfica, 2004.

FERRAZ, D.K. O papel da vegetação na margem de ecossistemas aquáticos. In: PRIMACK, R.B.; RODRIGUES, E. Biologia da conservação. Londrina: Editora Midiograf, 2001, p108-109 (Quadro 2.4).

FUREGATO, M.C.H. Parque Urbano Orquidário Municipal de Santos/SP: equipamento de lazer e turismo. Santos: Patrimônio: lazer e cultura, 2001. Disponível <http://www.unisantos.br/pos/revistapatrimonio/artigos. php?cod=36>, 2006.

GOMES-POMPA, A.; KAUS, A. Taming the wilderness myth. Bioscience, (S.I) V.42, nำ 1992.

IBAMA. Roteiro metodológico de planejamento: parque nacional, reserva biológica, estação ecológica. Brasília, 2002.

IBGE. Manual Técnico da Vegetação Brasileira. Rio de Janeiro, 1992. IUCN. Managing protected areas in the tropics. Gland, Switzerland, 1986.

IUCN. Guidelines for Protected Area Management Categories. Gland: Switzerland and Cambridge, UK: IUCN, 1994.

INSTITUTO BRASILEIRO DE DESENVOLVIMENTO FLORESTAL - IBDF E FUNDAÇÃO BRASILEIRA PARA A CONSERVAÇÃO DA NATUREZA - FBCN. Plano de sistema de unidades de conservação do Brasil. II etapa. Brasília, 1979.

LEITAO FILHO, H.F.; AZEVEDO, D. Critérios gerais para implantação de um parque ecológico. Campinas: UNICAMP, 1989.

LOMBARDO, M. A. Ilha de calor nas metrópoles: o exemplo de São Paulo. São Paulo: Hucitec, 1985. 244p. 
MACHADO, P.A.L. Direito Ambiental brasileiro. São Paulo: Malheiros, 2000.

MARQUES, A.C.; NUCCI, J.C. Planejamento, gestão e plano de manejo em unidades de conservação. Revista Ensino e Pesquisa (União da Vitória), v. 4, p. 33-39, 2007.

MORSELLO, C. Áreas protegidas públicas e privadas: seleção e manejo. 2.ed, São Paulo: Annablume, FAPESP, 2001.

OLIVEIRA, A.L.C.; MARQUES, J.S. Uma visão geográfica sobre unidades de conservação: o caso do município do Rio de Janeiro. X Simpósio Brasileiro de Geografia Física Aplicada, Rio de Janeiro: Anais..., UERJ, 2003, p.1-9. Disponível em: http://geografia.igeo.uerj.br/xsbgfa/cdrom/eixo3/3.3/137/137.htm. Acesso em: Maio de 2004.

PHILLIPS, A. Management Guidelines for IUCN Category V Protected Areas Protected landscapes/Seascapes. World Commission on Protected Areas (WCPA). Gland: IUCN The World Conservation Union, 2002. Best Practice Protected Area Guidelines Series No. 9.

PRIMACK, R.B.; RODRIGUES, E. Biologia da conservação. Londrina: Editora Midiograf, 2001.

RISSO, L.C. Cultura caiçara: chave para a conservação ambiental - um estudo em Picinguaba - Ubatuba - SP. Rio Claro, UNESP, 1998. Monografia (trabalho de graduação em Geografia), Instituto de Geociências e Ciências Exatas, UNESP, Rio Claro, 1998.

RISSO, L.C. Mapeamento das áreas suscetíveis à prática agroecológica no Núcleo Picinguaba (Parque Estadual da Serra do Mar) Ubatuba - SP, como subsídio à atividades sustentáveis. Rio Claro: UNESP, 2001. Dissertação (Mestrado em Conservação e Manejo de Recursos), Centro de Estudos Ambientais, UNESP, Rio Claro, 2001.

RISSO, L.C. Estudo de percepção e conservação do parque ecológico de Ourinhos SP. Relatório final FAPESP, 2009.

RODRIGUES, E. Edge effects on the regeneration of Forest fragments in south Brazil. Cambridge: Harvard University, 1998.

ROMARIZ, D.A. Aspectos da vegetação do Brasil. São Paulo, Edição da autora, 1996.

SECRETARIA DO MEIO AMBIENTE DO ESTADO DE SÃO PAULO. Mapa das unidades de conservação e produção do Estado de São Paulo. IF/SMA, 1997. 
ROSS, J. L. S. Análise Empírica da Fragilidade dos Ambientes Naturais e Antropizados. Revista do Departamento de Geografia. n.8, p.63-74, 1994.

ROSS, J.L.S. Ecogeografia do Brasil: subsídios para planejamento ambiental. São Paulo: Oficina de textos, 2006.

SHIMABUKURO, T.T. Participação Pública na elaboração de Plano de Manejo para Parques Urbanos: Estudo de caso na Bacia Hidrográfica do Ribeirão Viracopos. Município de Campinas, SP. Campinas, 2003.

SILVA, W.S.; FORNASARI FILHO, N. Unidades de conservação ambiental e áreas correlatas no Estado de São Paulo. São Paulo: IPT, 1992.

SIMMONS, I.G. Ecología de los recursos naturales. Barcelona: Ed.Omega, 1982.

THOMAS, K. O Homem e o mundo natural. São Paulo: Companhia das Letras, 1988.

TONHASCA JUNIOR, A. Ecologia e História Natural da Mata Atlântica. Rio de Janeiro: Interciência, 2005.

TUAN, Yi-Fu. Topofilia: um estudo da percepção, atitudes e valores do meio ambiente. São Paulo: Difel, 1980.

VIANNA, L.P. Considerações críticas sobre a construção da idéia de população tradicionais no contexto das unidades de conservação. São Paulo: USP, 1996. Dissertação (Mestrado em Geografia), Faculdade de Filosofia, Ciências e Letras, USP, São Paulo, 1996.

WARD, B.; DUBOS, R. Uma terra somente: a preservação de um pequeno planeta. São Paulo: Edgard Blucher, Melhoramentos, Ed. da Universidade de São Paulo, 1973.

WHITE, L. The symbol: the origin and basis of humans behavior. In: MORBEL, L.; SMITH (orgs). Readings of anthropology. Nova York: McgrawHiel, 1955. 